\title{
Enlightenment of Theme-Rheme Theory to English Writing Teaching
}

\author{
Song $\mathrm{Hu}$ \\ Dalian Jiaotong University, Dalian, 116021, China
}

Keywords: theme-rheme theory; English writing

\begin{abstract}
Among the four skills, i.e. listening, speaking, reading and writing of English learning, writing is the weakest link for the Chinese students. From one of the theories of system-functional linguistics, i.e. the theme-rheme theory, an effective solution is explored and the application of theme-rheme theory in reading and writing can improve the students' writing ability.

With China joining the WTO, more and more people have emphasized the improving of English writing ability. According to the large-scale and high-creditability CT 4 nationwide, although the passing rate of CET increases overall, the average score of writing is lower than other scores. According to the sampling investigation on the score of nationwide CET-4 unified examination of undergraduate students in a key university and ordinary university in a province in June 2004, it can be seen that the writing had the lowest score, indicating that the writing level of students is asynchronous with other abilities.
\end{abstract}

\section{Theme-rheme theory and thematic progression model}

The concept of theme and rheme was proposed by the founder of Prague School and Czechic linguist Mathesius in 1939, who researched the role played by sentences in the linguistic communication of different components, and summarized that the component at the beginning of the sentence played a special role, i.e. to introduce the topic. He called this part theme, and others parts rheme. Theme generally represent the known information, while the rheme generally represents the unknown information. The system-functional school represented by Halliday accepted this pair of term proposed by the Prague School, but had different opinions in the division of theme. Halliday proposed and distinguished simple theme, multiple theme and clausal theme in the book Introduction to System-functional Grammar in 2000. In the simple theme, he distinguished unmarked and marked, and in the multiple theme, he further divide textual theme, interpersonal theme and topic theme. With such opinion of Halliday, Hu Zhuanglin made an explanation in the book Link and Coherence of Text written in 1994.

Most of the texts constructed by the producer of thematic progression model consists of two or above sentences, and there will be certain connection and change between the theme and theme, rheme and rheme and theme and rheme in the front and rear sentences, and such connection and change is called progression. The most common thematic progression includes the following four types. The first type is radiation type, i.e. several sentences have the same theme, but different rheme. For example, She was born into the old society and unfortunately into a poor family. She didn't do anything remarkable during her life. She had to take up the responsibility of taking care of her younger sisters and brothers. The second type is aggregate type, i.e. several sentences have different theme, but have consistent rheme, for example, China is in Asia. Japan is in Asia. And Indiais in Asia , too. The third type is step type, i.e. the theme of the rear sentence is the rheme of the previous sentence, for example Mary bought a carpet. It was made in Turkey. Turkey is a country in Asia. The fourth type us cross type, i.e. the theme and rheme of the rear sentence mutually cross or partially cross with the theme and rheme of the previous sentence, for example, :Mary bought a carpet. It was very experience. Mary liked expensive things. An excellent composition generally needs the combined use of several thematic progression models. 


\section{Application of theme-rheme theory in college English writing}

We mainly conduct sample investigation on the CET simulation examination of the non-English major students. The total score in the writing part is 15 scores. According to the scoring condition, we divide the composition into five grades: 14 scores, 11 scores, 8 scores, 5 scores and 2 scores. Except the compositions of 2 scores, we sample 10 compositions of each other grades for analysis. First, we analyze the theme type, it can be seen that the score is directly connected to the type of theme used. The compositions with the most multiple theme and clausal theme have the highest score, and those with the fewest multiple theme and clausal theme have the lowest score. So it can be seen that the number of multiple theme and clausal theme used is of direct proportion to the final score.

\section{Suggestions on English writing teaching}

Improve the students' writing ability through wide reading. Reading a lot of English articles can help students understand the thinking mode of the westerners, and master the textural structure of westerners in reading. During reading, teachers should appropriately introduce the theme theory and thematic progression model to the students, so that the students can gradually form the habit of English thinking. By improving the students' writing ability through a lot of exercises, teachers can start from the topic of composition and ask students to modify the composition topic according to the theme theory and theme progression model, so as to form a habit of using this theory. In addition, during the composition practice of students, teachers should make evaluation well, and help students analyze the language, content and structure of the excellent compositions. First, help students master how to distinguish the theme and rheme and use the iconic theme. Appropriately using multiple theme, clausal theme and iconic theme can make the articles rich and attractive. Second, guide students to correctly use the thematic progression model and make clear the logic meaning between sentences. Some articles linking well in appearance actually are not the texts with semantic cohesion, but the combination of words without any semantic connection, for example, bought a Ford. A car in which President Wilsonrode down the Champs Elysees was black. Black English has been widely discussed1. The discussion between the presidents ended last week. A week has seven days. Every day I feed my cat. The cat is on the mat. Mat has three letters. Although this sentence follows the thematic progression model of step type, i.e. the theme of the rear sentence is the rheme of the previous sentence, there is no connection between the rheme of the precious sentence and the theme of the rear sentence. The semanteme between them is meaningless, and this phenomenon is the pseudo-coherence or no coherence called by Halliday. Therefore, teachers must correctly guide students to use the thematic progression model, and should not mistakenly think that the article with thematic progression model is a good article of semantic coherence. In a word, the focus of English writing currently should be put on the whole textual structure, but not the specific vocabulary and grammar structure. The theme-rheme theory and thematic progression model play an important role for the development of the whole text. Guiding students to master and apply this theory is helpful to improve the students' writing ability. It is known to us all that the improving of writing ability is an increasingly gradual process. Therefore, the English writing teachers and students should make efforts persistently and unremittingly.

\section{References:}

[1 ] M.A.K. Halliday . An Introduction to Functional Grammar Second edition[M] . Beijing: Foreign Language Teaching and Research Press, 2000

[2] Hu Zhuanglin, Link and Coherence of Text [M], Shanghai: Shanghai Foreign Language Education Press, 1994 
[3] Zhu Yongsheng, Yan Shiqing, Multi-dimension Thinking on System-functional Linguistics [M], Shanghai: Shanghai Foreign Language Education Press, 2001

[4] Hu Zhuanglin, Zhu Yongsheng, Zhang Delu, Li Zhanzi, Introduction to System-functional Linguistics [M] 